\title{
ASSOCIATION BETWEEN THE SPEAKING SPACE OF /S/ SOUND AND INCISAL OVERLAPS IN DENTATE AND EDENTATE SUBJECTS
}

\author{
ASSOCIAÇÃO ENTRE O ESPAÇO DE PRONÚNCIA DO SOM /S/ E OS TRESPASSES INCISAIS \\ EM INDIVÍDUOS DENTADOS E EDENTADOS
}

Raphael Freitas de SOUZA ${ }^{1}$, Marco Antonio COMPAGNONI², Cláudio Rodrigues LELES ${ }^{3}$, Karina Buainain de Freitas SADALLA ${ }^{4}$

\author{
1- DDS, MSc, Graduate student, Department of Dental Materials and Prosthodontics, Araraquara Dental School, São Paulo State University, \\ Brazil. \\ 2- DDS, MS, PhD, Chairman, Department of Dental Materials and Prosthodontics, Araraquara Dental School, São Paulo State University, \\ Brazil. \\ 3- DDS, MS, PhD, Associate Professor, Department of Prevention and Oral Rehabilitation, School of Dentistry, Federal University of Goiás, \\ Brazil. \\ 4- DDS, Graduate student, Department of Dental Materials and Prosthodontics, Araraquara Dental School, São Paulo State University, Brazil. \\ Corresponding address: Prof. Dr. Marco Antonio Compagnoni - Department of Dental Materials and Prosthodontics - Rua Humaitá, 1680, \\ Centro - 14801-903 Araraquara, SP, Brazil. Phone +55-16-3301-6411 Fax: +55-16-3301-6406 e-mail: compagno@foar.unesp.br \\ Received: October 18, 2004 - Modification: August 09, 2005 - Accepted: September 13, 2005
}

\begin{abstract}
$T_{\text {te }}$

Le purpose of this study is to determine the association of speaking space of /s/ sound with vertical and horizontal overlaps for two subject groups. Group I comprised 61 subjects with complete permanent dentition and Group II comprised 33 complete denture wearers. They had their mandibular movement determined by using an electromagnetic method. Speaking space of /s/ was obtained from each subject as they were instructed to say the word 'seis' three times. The mean interocclusal distance during /s/ production was considered the speaking space of /s/. Vertical and horizontal incisor overlaps were also measured. The mean value of speaking space of /s/ was $2.22 \mathrm{~mm}( \pm 1.38)$ for Group I and $2.61 \mathrm{~mm}( \pm 1.53)$ for Group II. In Group I, significant correlations were found between the speaking space of $/ \mathrm{s} /$ and vertical overlap ( $\mathrm{r}=0.36, \mathrm{P}<0.01$ ), and between speaking space of $/ \mathrm{s} /$ and horizontal overlap $(\mathrm{r}=0.45, \mathrm{P}<0.01)$. In Group II, no significant correlation was found between speaking space of $/ \mathrm{s} /$ and the overlaps. It was concluded that incisor overlap had a direct influence on the measure of speaking space of /s/ for dentate subjects, but this association was not present for complete denture wearers.

Uniterms: Phonetics; Dental occlusion; Complete denture; Jaw relation record.
\end{abstract}

\section{RESUMO}

Q

objetivo deste estudo foi determinar a associação do espaço de pronúncia do som /s/ com os trespasses vertical e horizontal em dois grupos de indivíduos. O Grupo I foi formado por 61 indivíduos com dentição permanente completa e o Grupo II por 33 usuários de próteses totais. Todos tiveram seus movimentos mandibulares determinados por um método eletromagnético. O espaço de pronúncia do /s/ foi obtido em cada indivíduo conforme eram instruídos a dizer a palavra 'seis' por três vezes. A distância interoclusal média durante a produção do /s/ foi considerada como sendo o espaço de pronúncia do /s/. Os trespasses incisais vertical e horizontal também foram mensurados. Os valores médios do espaço de pronúncia do /s/ foram $2.22 \mathrm{~mm}$ ( \pm 1.38) para o Grupo I e $2.61 \mathrm{~mm}( \pm 1.53)$ para o Grupo II. Para o Grupo I, observou-se associação entre o espaço de pronúncia do /s/ e os trespasses vertical ( $\mathrm{r}=0.36, \mathrm{P}<0.01$ ) e horizontal ( $\mathrm{r}=0.45, \mathrm{P}<0.01$ ). Para o Grupo II, não foi encontrada nenhuma correlação significante entre o espaço de pronúncia do /s/ e os trespasses. Concluiu-se que o trespasse incisal teve influência direta sobre as medidas do espaço de pronúncia do /s/ em indivíduos dentados, mas esta associação não esteve presente nos usuários de próteses totais.

Unitermos: Fonética; Oclusão dentária; Prótese total; Registro da relação maxilomandibular. 


\section{INTRODUCTION}

The phonetic method is one of the several techniques to determine vertical dimension of occlusion in dentate and edentate patients. This method was proposed by Silverman ${ }^{26,27}$ and is based on sibilant sounds. He defined the closest distance of the mandible to the maxilla as the closest speaking space ${ }^{28}$. This technique has been widely accepted, mainly because of the supposed stability of mandibular speaking positions, even after removal of teeth ${ }^{14}$. Another advantage of this technique is the smaller variance of closest speaking space when compared to freeway space ${ }^{21}$.

According to Silverman ${ }^{26-28}$, the sibilant sounds are the ones that most constantly bring the mandible to the closest speaking level. The sibilants are high-frequency sounds produced by a stream of air directed through a minimal incisal separation $^{4}$ and an example of it is the /s/ sound. Its mandibular speaking position has been used for vertical dimension evaluation and also as a parameter for placing anterior artificial teeth ${ }^{7,15,18,19}$. Tongue contacts the lingual portion of anterior teeth during /s/ sound and their position in a complete denture can affect emission quality ${ }^{22,25}$. Speech movements can also be influenced by anatomo-functional factors such as incisor overlaps, face format and tongue movements ${ }^{29}$.

Some studies that used dentate subjects showed association between incisor overlaps and speaking spaces. Benediktsson $^{1}$ found a marked influence of overlaps on the movements and position of the mandible in /s/ sound production. Murrel ${ }^{15}$ and Pound ${ }^{18,19}$ proposed the /s/ sound as a critical guide to establish interocclusal relationships for edentate patients. It was reported that the correlation between vertical overlaps and the closest speaking space is significant $t^{5,16}$.

The behavior of the speaking spaces in edentulous subjects has not been critically tested. Since denture wearers must adapt their speech to the prosthetic condition, additional data are needed to assess the effect of anatomical factors, i.e., the incisor overlaps, on the phonetic method. It is not known whether an artificial dentition can influence mandibular speaking positions in edentulous patients.

Most clinical research on closest speaking space has been done in English language, but it is recognized that this can vary in different languages ${ }^{12}$. The measure for the speaking space of /s/ (SSS) in Portuguese speakers is not known. The purpose of this study is to investigate the association between the SSS and incisor overlaps in dentate and edentulous subjects from a sample of Portuguese speakers.

\section{MATERIALS AND METHODS}

\section{Subjects}

Ninety-four subjects voluntarily participated in the study and were divided into two groups. Only subjects with good general and oral health were included and none presented speech defects or had signs or symptoms of temporomandibular dysfunction. Group I comprised 61 subjects (25 men and 36 women) with mean age of 30.26 years $( \pm 12.71)$. All of them had permanent teeth and had no fixed or removable prostheses or orthodontic appliance. The subjects retained their 12 anterior teeth and presented stable maximal intercuspation. Group II included 33 edentulous subjects (10 men and 23 women) with mean age of 59.18 years $( \pm 10.00)$. They were selected among the patients treated at the Prosthodontics Clinics of Araraquara Dental School, São Paulo State University. All had been wearing the same pair of complete dentures for a minimum period of six months and a maximum of two years. During complete denture treatment, assessment of the vertical dimension of occlusion was made as follows ${ }^{23}$ : each subject was instructed to reach the resting position after licking their lips, swallowing and saying $/ \mathrm{m} /$. This procedure was repeated three times and the mean distance from the chin to the base of the nose, minus $3 \mathrm{~mm}$, was considered as the vertical dimension of occlusion. Following these measurements, an esthetic appraisal was carried out with the occlusion rims in position. Finally, the vertical dimension of occlusion was assessed by the phonetic test of Silverman ${ }^{26-28}$. The occlusion rims should not contact during the production of sibilant sounds.

This research project was approved by the institutional Ethics Committee. All participants were informed on the nature of the investigation and agreed to participate.

\section{Kinesiographic equipment}

Mandibular movements were recorded by the kinesiograph of the K6-I Diagnostic System (Myotronics Research Inc., Seattle, WA, USA). The equipment consisted of an array of sensors placed on the subject's head that provided information about the position of the mandible. When the mandible moved, changes in the magnetic flux of the small bar magnet attached to the mandibular incisor teeth were detected. The kinesiograph was connected to a computerized system that records and displays spatial coordinates in the vertical and anteroposterior axes to the nearest $0.1 \mathrm{~mm}$.

\section{Research protocol}

The subjects were placed on a dental chair with head and trunk at an orthostatic position in a single session. All were instructed not to change neck inclination during the kinesiographic exam, which was conducted in a single session.

First of all, the SSS was evaluated. This variable can be defined as the mandibular movement from the emission of / s/ sound until maximal intercuspation. Each subject was asked to repeat the word 'seis' three times. Since this word contains two emissions of the /s/ sound, the variable was recorded six times and was present at two positions: initial and final. The mean of the six measures (in mm) was considered the individual value for the variable. As the 
tracing describes each axis separately, the resulting SSS was the movement that was originated from the two vectors. Thus, three measures were collected: vertical, anteroposterior and resulting.

In kinesiographic analysis, records provided measurements at separate axes, but did not show how much the mandible moved in oblique orientation (resulting movement). These measurements were calculated by Pythagoras' equation $\left(a^{2}=b^{2}+c^{2}\right.$, where ' $a$ ' is the resulting value, ' $b$ ' is the mean value at vertical axis and ' $c$ ' is the mean movement at the anteroposterior orientation).

The vertical and horizontal incisor overlaps were measured directly at the time of kinesiographic assessment. Each subject moved the mandible to the edge-to-edge position. Then, the subjects were asked to assume the maximal intercuspation. The movement recorded in the vertical axis consisted of the vertical overlap and the anteroposterior axis provided the horizontal overlap.

Statistical analysis was performed by parametric tests to compare groups (paired and unpaired Student's $t$ test) and to evaluate association between variables (Pearson's correlation test). The level of significance was a $=0.05$. Data were evaluated by the program SPSS for Windows - Version 7.5.1, 1996 (SPSS Inc., Chicago, Il, USA).

\section{RESULTS}

Mean SSS for the two groups according to each axis is shown in Table 1. In anteroposterior axis, positive values represent protrusion, and negative ones mean mandibular retrusion.

Table 2 illustrates the results obtained for vertical and horizontal overlaps.

TABLE 1- Mean values for SSS (in $\mathrm{mm} ; \pm$ standard deviation) according to vertical and anteroposterior axes and resulting measures

\begin{tabular}{lll}
\hline SSS - Axes & Group I & Group II \\
\hline Vertical & $1.79( \pm 1.17)$ & $2.50( \pm 1.37)$ \\
Anteroposterior & $0.90( \pm 1.18)$ & $-0.70( \pm 0.78)$ \\
Resulting & $2.23( \pm 1.35)$ & $2.67( \pm 1.47)$ \\
\hline
\end{tabular}

TABLE 3- Pearson's correlation coefficients for Group I (n $=61$ ). SSS and overlaps

SSS - Axes Vertical Overlap

Horizontal Overlap

\begin{tabular}{lll}
\hline Vertical & $0.42^{\star \star}$ & $0.39^{\star \star}$ \\
Horizontal & 0.13 & $0.35^{\star \star}$ \\
Resulting & $0.36^{\star \star}$ & $0.45^{\star \star}$ \\
\hline
\end{tabular}

* Significant at $5 \%$ level

** Significant at $1 \%$ level
The subjects were evaluated by gender. No difference was found for the SSS, as shown by the unpaired ' $\mathrm{t}$ ' test (Group I: $P=0.98$ e Group II: $P=0.92$ ). Age did not influence measures either. Correlation coefficients between age and SSS were - 0.16 (Group I) and 0.12 (Group II) and were not significant.

Comparisons between SSS means at initial and final positions were not statistically significant for either Group I or Group II (paired 't' test; $P=0.95$ and 0.050067, respectively).

Tables 3 and 4 show correlation coefficients between SSS and overlaps. A trend of a wider SSS in association to greater vertical and horizontal overlaps was found for Group I. Subjects with larger horizontal overlaps had more mandibular protrusion during /s/ sound. In addition, those with broader vertical overlaps had greater mandibular opening. Nevertheless, edentate subjects (Group II) did not express significant correlation values between overlaps and resulting or axial SSS values.

\section{DISCUSSION}

The present study obtained a mean SSS of $2.23 \mathrm{~mm}$ for dentate subjects (Group I). These results are close to those found by other studies for the closest speaking space ${ }^{2,4}$ and for the $\mathrm{SSS}^{8}$. Gillings ${ }^{9}$ reported the closest speaking space as being $2.5 \mathrm{~mm}$, although this value can be higher than real because the equipment used could have exerted significant weight over the mandible.

This investigation indicates that the SSS in Portuguese speakers is similar to the closest speaking space of English speakers ${ }^{2-5,7,9,26-28}$. Lu, et al. ${ }^{12}$ stated that the /s/ sound is responsible for the smallest distance from the mandible to the maxilla during speech for Cantonese subjects. Burnett and Clifford $^{4}$ found that a single sibilant sound does not

TABLE 2- Vertical and horizontal overlap mean values (in $\mathrm{mm} ; \pm$ standard deviation)

\begin{tabular}{lcc}
\hline Incisor overlaps & Group I & Group II \\
\hline Vertical & $2.18( \pm 1.29)$ & $1.04( \pm 0.56)$ \\
Horizontal & $2.94( \pm 1.55)$ & $2.29( \pm 1.28)$ \\
\hline
\end{tabular}

TABLE 4- Pearson's correlation coefficients for Group II (n $=33$ ). SSS and overlaps

\section{SSS - Axes Vertical Overlap}

Horizontal Overlap

\begin{tabular}{lll}
\hline Vertical & 0.01 & 0.04 \\
Horizontal & 0.19 & 0.12 \\
Resulting & -0.01 & 0.02 \\
\hline
\end{tabular}

* Significant at $5 \%$ level

** Significant at $1 \%$ level 
always produce the closest speaking space. Nevertheless, the difference between the closest and each sibilant speaking space was small and its practical significance is questionable.

The placement of the /s/ sound in the initial or final word position had no effect on the SSS measurement. Burnett ${ }^{3}$ and Lundqvist, et al. ${ }^{13}$ found similar results for sibilant sounds. This refutes the suggestion that a smaller SSS for Cantonese speakers $-1.16 \mathrm{~mm}$ - can be explained by a more constant position of the $/ \mathrm{s} /$ in the language ${ }^{12}$.

Edentulous subjects (Group II) presented a mean SSS of $2.67 \mathrm{~mm}$. For the anteroposterior movement, Group II showed a distinct behavior when compared to Group I. While dentate subjects tended to protrusion during /s/ production, denture wearers tended to retrusion. Since no association was found between SSS and age for each group, we can infer that the prosthetic situation is responsible for this finding. Thickness of prosthesis at palatal area was pointed out as a possible cause of speech defects ${ }^{10,17,24,25}$. Regarding mandibular movement, Geissler ${ }^{7}$ did not find alterations during /s/ sound after the placement of a 3 mm-thick resin plate over the palate of dentate subjects. However, Lundqvist, et al. ${ }^{13}$ verified a smaller mandibular movement during /s/ production immediately after a similar experiment.

Silverman ${ }^{28}$ described a protrusive movement in dentate subjects during /s/ sound production. According to this author, this movement must be preserved after tooth losses in order to have successful prosthetic rehabilitation. This pattern was found in most of Group I subjects, but not in Group II. This kinesiographic alteration can be explained by a more posterior position of the tongue that needs compensatory movements of articulating organs ${ }^{24}$. Thus, this protrusive movement is not compatible with the situation observed for edentulous subjects.

The closest speaking space in dentate subjects shows a low intra-individual variation ${ }^{20,21}$. Nevertheless, further studies are needed to elucidate the precision of speaking spaces after tooth loss and denture wearing.

\section{Influence of incisor overlaps}

In dentate subjects (Group I), moderate correlation coefficients were found between the overlaps and SSS. Data showed positive correlation between vertical overlap and closest speaking space in English ${ }^{5,7,11}$ and Spanish ${ }^{16}$. Benediktsson $^{1}$ showed a distinct tendency to protrusion related to raised overjets, regardless of the degree of overbite. These results are reinforced by our study that found these trends as well.

A discrete positive correlation between vertical mandibular opening during /s/ production and horizontal overlap was found. This way, the assertion that smaller vertical openings during sibilant pronunciation follow wider horizontal overlaps ${ }^{9}$ was not confirmed. Present results showed that subjects with broader vertical overlaps tended to larger vertical movements during /s/ articulation, and a similar association was found between horizontal overlap and mandibular protrusion.
Previous studies proposed that SSS width is controlled by the position of anterior teeth ${ }^{15,18,19}$. The authors stated that incisor borders of mandibular teeth should be placed 1 mm below the border of maxillary teeth during /s/ articulation. On the other hand, low correlation that was found in the present research disagrees that SSS is always wider than vertical overlap. These data are in accordance to those of Burnett and Clifford ${ }^{5}$, who stated that the result of these techniques is the obtainment of excessively ample speaking spaces during prosthetic rehabilitation.

Regarding Group II, there was no association between incisor overlaps and SSS. These data suggest that SSS was not influenced by the standard positioning of artificial anterior teeth. A possible explanation is that complete denture insertion results in a vast number of anatomic alterations in the oral cavity. In other words, phonetic adaptation to the dentures depends on individual answer to several factors, with emphasis to palatal anatomy $7,10,13,17,24,25$.

The analysis used in this study had some special limitations regarding the edentulous subject. Regarding mean values and dispersion obtained for vertical and horizontal overlaps of edentulous subject, we can notice that extreme situations were not evaluated. A denture wearer could react to vast overlaps with compensatory movements. This assertion is valid for both kinesiographic pattern and speech quality. Additionally, the methodology had not assumed the displacement of the mucosa ${ }^{6}$. Thus, the results may not reflect the exact measurement of the incisal overlaps. However, it is considered that the correlation between the variables is realist, since the relative differences between the obtained measurements strongly depend on the anterior occlusion.

\section{CONCLUSIONS}

Based on the present study, we can conclude that SSS has great inter-individual variation. SSS had positive correlation with vertical and horizontal incisor overlaps in dentate subjects. Nevertheless, this association was not found in complete denture wearers.

\section{ACKNOWLEDGEMENTS}

This research was supported by the National Council of Scientific and Technological Development (CNPq - grant no. 1311340/2001-8) and the São Paulo Council of Research (FAPESP - grant no. 01/06159-4). We also thank Solange Aranha for proofreading the English version. 


\section{REFERENCES}

1- Benediktsson E. Variation in tongue and jaw position in "s" sound production in relation to front teeth occlusion. Acta Odontol Scand. 1958; $15: 275-303$.

2- Burnett CA. Reproducibility of the speech envelope and interocclusal dimensions in dentate subjects. Int J Prosthodont. 1994;7:543-8.

3- Burnett CA. Mandibular incisor position for English consonant sounds. Int J Prosthodont. 1999;12:263-71.

4- Burnett CA, Clifford TJ. Closest speaking space during the production of sibilant sounds and its value in establishing the vertical dimension of occlusion. J Dent Res. 1993;72:964-7.

5- Burnett CA, Clifford TJ. The mandibular speech envelope in subjects with and without incisal tooth wear. Int J Prosthodont. 1999;12:514-8.

6- Compagnoni MA, Souza RF, Leles CR. Kinesiographic study of complete denture movement related to mucosa displacement in edentulous patients. Pesqui Odontol Bras. 2003;17:356-61.

7- Geissler PR. Studies of mandibular movements in speech. J Dent 1975;3:256-60.

8- George JP. Using the kinesiograph to measure mandibular movements during speech: a pilot study. J Prosthet Dent. 1983;49:263-70.

9- Gillings BRD. Jaw movements in young adult men during speech. J Prosthet Dent. 1973;29:567-76.

10- Hamlet SL, Stone M. Speech adaptation to dental prostheses: the former lisper. J Prosthet Dent. 1982;47:565-9.

11- Howell PGT. Incisal relationship during speech. J Prosthet Dent. 1986;56:93-9.

12- Lu GH, Chow TW, So LKH, Clark RKF. A computer-aided study of speaking spaces. J Dent. 1993;21:289-96.

13- Lundqvist S, Karlsson S, Lindblad P, Rehnberg I. An electropalatographic and optoeletronic analysis of Swedish [s] production. Acta Odontol Scand. 1995;53:372-80.

14- Mehringer EJ. The use of speech patterns as an aid in prosthodontic reconstruction. J Prosthet Dent. 1963;13:825-36.

15- Murrel GA. Phonetics, function and anterior teeth. J Prosthet Dent. 1974;32:23-31.

16- Peraire M, Salsench J, Torrent J, Nogueras J, Samsó J. Study of mandibular movement during speech. Cranio. 1990;8:324-31.

17- Petrovic A. Speech sound distortions caused by changes in complete denture morphology. J Oral Rehabil. 1985;12:69-79.

18- Pound E. The mandibular movements of speech and their seven related values. J Prosthet Dent. 1966;16:835-43.

19- Pound E. Let /S/ be your guide. J Prosthet Dent. 1977;38:482-9.

20- Rivera-Morales WC, Mohl ND. Anteroposterior and mediolateral variability of the closest speaking space. Int J Prosthodont. 1990;3:179-84.

21- Rivera-Morales WC, Mohl ND. Variability of closest speaking space compared with interocclusal distance in dentulous subjects. J Prosthet Dent. 1991;65:228-32.
22- Runte C, Lawerino M, Dirksen D, Bollmann F, LamprechtDinnesen A, Seifert E. The influence of maxillary central incisor position in complete dentures on /s/ sound production. J Prosthet Dent. 2001;85:485-95.

23- Russi S, Lombardo JG, Compagnoni MA, Nogueira SS. Prótese total clínica. Araraquara: Faculdade de Odontologia de Araraquara; 1982.

24- Schierano G, Mozzati M, Bassi F, Preti G. Influence of the thickness of the resin palatal vault on the closest speaking space with dentures. J Oral Rehabil. 2001;28:903-8.

25- Seifert E, Runte C, Riebandt M, Lamprecht-Dinnesen A, Bollmann F. Can dental prostheses influence vocal parameters? J Prosthet Dent. 1999;81:579-85.

26- Silverman MM. Accurate measurement of vertical dimension by phonetics and the speaking centric space. Part I. Dent Dig. 1951;57:261-5.

27- Silverman MM. Accurate measurement of vertical dimension by phonetics and the speaking centric space. Part II. Dent Dig. 1951;57:308-11.

28- Silverman MM. The speaking method in measuring vertical dimension. J Prosthet Dent. 1953;3:193-9.

29- Tipnis AK. A preliminary survey into the association of the Frankfurt-mandibular-plane Angle with interdental 's' and incisor relationship. Dent Pract. 1971;21:258-60. 